\title{
¿Están formados los profesionales que imparten cursos post-grado?
}

\section{Mercedes Miguel Montoya}

Unidad de Hemodiálisis Hospital Universitario Central de Asturias

\section{Señora Directora:}

A pesar de que llevamos muchos años impartiendo docencia y realizando cursos post-grado para enfermeros de diálisis (20 años desde nuestro primer curso), los cambios estructurales surgidos en los dos últimos años, como consecuencia de la fusión de dos Servicios de Nefrología, con las consiguientes variaciones en el equipo humano, nos han Ilevado a considerar el perfil que tiene el equipo de enfermería resultante y a plantearnos si el mismo cuenta con las suficientes competencias (conocimientos, habilidades y actitudes) para impartir con calidad los cursos de Experto Universitario de Enfermería en Diálisis, tal y como venimos haciendo desde 1996.

\section{Objetivos}

Conocer la capacidad docente de los profesionales de enfermería de la Unidad de Hemodiálisis de nuestro Hospital, en cuanto a cursos post-grado de la especialidad en que trabajamos (Nefrología/Diálisis), y la experiencia adquirida en función de los años de trabajo en la misma.

\begin{tabular}{|c|}
\hline Correspondencia: \\
Mercedes Miguel Montoya \\
Unidad de Hemodiálisis \\
Hospital Universitario Central de Asturias \\
C/ Celestino Villamil s/n \\
33006 Oviedo \\
Correo: mercedes.miguel@sespa.princast.es \\
\hline
\end{tabular}

\section{Material y métodos}

Se realizó una encuesta anónima al personal de enfermería de la Unidad de Hemodiálisis, donde se preguntaba: años de profesión, antigüedad en Nefrología, años impartiendo docencia; y si se era socio de la Sociedad Española de Enfermería Nefrológica (SEDEN) o de la Asociación Europea de Enfermería de Diálisis y Trasplante (EDTNA).

Asimismo se preguntaba, si se había realizado algún curso complementario como por ejemplo los impartidos en nuestra Unidad o los que organiza la SEDEN.

- Curso de Perfeccionamiento Profesional para Enfermería Nefrológica (Diálisis), 1986-1987 de 122 horas.

- Curso de Experto Universitario de Enfermería en Diálisis de 270 horas.

- Curso de Acreditación de Conocimientos Especializados para Enfermería Nefrológica.

- Actualización de Conocimientos para Enfermería Nefrológica.

Se podía añadir además información referente a otros tipos de formación complementaria (cursos, talleres, jornadas, seminarios) relacionada con la $\mathrm{Ne}$ frología o con la comunicación y docencia en general.

\section{Resultados}

De las 20 encuestas entregadas, fueron contestadas 19. Los años de profesión de los enfermeros de la Unidad de Hemodiálisis oscilan entre 12 y 32 años, con una media de 26 años. La antigüedad en Nefro- 
logía es de 17 años de media con una desviación estándar de 6,7. Los años como docentes del nuevo equipo resultante de la fusión son muy variables, va de 2 a 25 años, con una media de 10 años (figura 1). Sobre la participación en las dos Sociedades de la Especialidad, 17 de los 19 enfermeros encuestados son socios de la SEDEN siendo sólo 7 socios de la EDTNA.

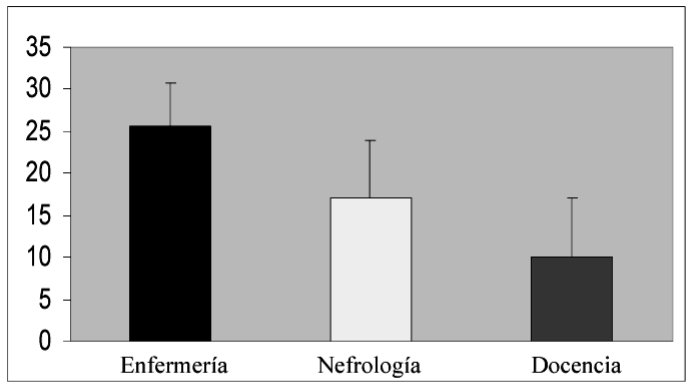

Figura 1: Años de antigüedad en Enfermería, Nefrología.y Docencia (media y desviación estándar).

Cuando se pregunta por los cursos post-grado realizados sobre la Especialidad 13 de los encuestados han realizado el Curso de Perfeccionamiento Profesional de Enfermería Nefrológica (Diálisis). El curso de Experto Universitario para Enfermería en Diálisis lo realizaron 16 enfermeros, que representa el $84 \%$ de la plantilla. El curso de Actualización de Conocimientos para Enfermería Nefrológica, que organiza la SEDEN, lo han hecho 9 enfermeros, y de éstos, hicieron la Actualización de Conocimientos para Enfermería Nefrológica el 7 personas (figura 2). A la pregunta sobre otros tipos de formación complementaria la totalidad de la plantilla había participado en varias actividades sobre diferentes temas.

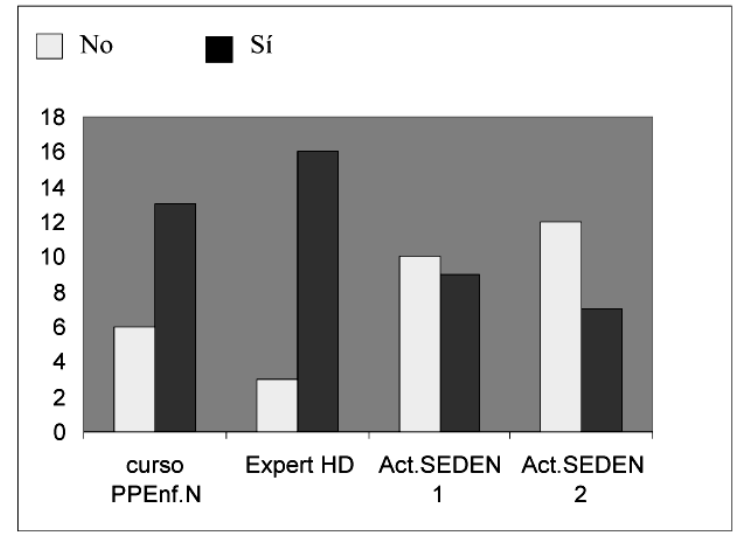

Figura 2: Realización de cursos postgrado del total de los encuestados. (PPEnf.N: Perfeccionamiento profesional de Enfermería Nefrológica, Act.: Curso d actualización).

\section{Conclusiones}

A la vista de los resultado de las encuestas, creemos que los profesionales de enfermería de la Unidad de Hemodiálisis están suficientemente formados, tanto práctica como teóricamente, para seguir impartiendo docencia, y formando a nuevos enfermeros en la práctica de la Diálisis, dado que prácticamente todo el personal tiene realizado el Curso de Experto, y tiene una antigüedad en Diálisis considerable (17 años de media). Es importante, no obstante, que mantengan una actitud positiva en cuanto a la formación continuada "formación a lo largo de la vida", para hacer frente a los nuevos avances científicos y tecnológicos, que les permita desarrollar su actividad con eficiencia y proporcionar cuidados de calidad, razón de ser de la profesión enfermera.

Agradecimientos

Al personal de enfermería de la Unidad, por su colaboración en este estudio. 